\title{
Binaytara Foundation's International Journal of Cancer Care and Delivery: Why?
}

\author{
Tara Shah ${ }^{1}$, Binay Shah ${ }^{1}$ \\ ${ }^{1}$ Binaytara Foundation \\ Keywords: international journal of cancer care delivery, binaytara foundation, cancer disparities \\ https://doi.org/10.53876/001c.27350
}

\section{International Journal of Cancer Care and Delivery}

Vol. 1, Issue 1, 2021

The science of oncology has made a steep progress in the last few decades with new molecules, biologics, and diagnostics developed for many types of cancers. Anticancer drugs and biologics accounted for a third of all new drugs approved by the Food \& Drug Administration (FDA) between 2009 and 2017.(Batta, Kalra, and Khirasaria 2020) Though these new developments have contributed to a notable decrease in cancer mortalities in the last few decades, access to these life-saving drugs and diagnostics remains a challenge for most of the non-western world as $88 \%$ of the new drugs released to the market between 2014 and 2019 were consumed in the United States and Western Europe, leaving less than $12 \%$ for the rest of the world.(Barrios, Reinert, and Werutsky 2019) Even in high-income countries like the United States, Canada, and the UK, new cancer drugs can be cost-prohibitive for many patients and are unsustainable for a country's healthcare system.(Rajkumar 2018) However, access to newer therapies is only one of the many factors that come into play when delivering care to cancer patients. Various other factors including socio-cultural, clinical, behavioral, environmental, biological, and genetic factors contribute to cancer health disparities.

Binaytara Foundation (BTF) is a 501c3 non-profit organization involved in improving access to cancer care by educating healthcare providers and community members, advocating for better access to care, and innovating program models and services that improve access to care. The BTF not only organizes a number of in-person as well as virtual continuing educational activities, but also offers free enduring contents to oncology providers.

Outside the United States, BTF has supported the establishment of Nepal's only bone marrow transplant center at Civil Service Hospital in collaboration with the University of Illinois at Chicago. This partnership brought a low-cost bone marrow transplant service to the 27 million people of Nepal. BTF's other accomplishments include establishment of hospice and palliative care programs in India and Nepal, and establishment of a 25-bed cancer hospital, the Binaytara Foundation Cancer Center (BTFCC) in Janakpurdham, Nepal. The BTFCC is the only cancer hospital in province 2 of Nepal, the most densely populated province with nearly 6 million people.

In view of significant cancer health disparities in the United States and globally and the need for innovative solutions to these important problems, the BTF leadership decided to establish the International Journal of Cancer Care and Delivery (IJCCD). The goal of IJCCD is to provide oncology professionals and researchers around the world a platform for sharing their research and experiences with barriers to cancer care delivery and effective solutions that they have identified, tested, and implemented to navigate those barriers.

Submitted: July 29, 2021 PST, Accepted: August 08, 2021 PST 


\section{REFERENCES}

Barrios, Carlos Henrique, Tomás Reinert, and Gustavo Werutsky. 2019. “Access to High-Cost Drugs for Advanced Breast Cancer in Latin America, Particularly Trastuzumab.” Ecancermedicalscience 13 (January). https://doi.org/10.3332/ecancer.2019.898.

Batta, Angelika, Bhupinder Singh Kalra, and Raj Khirasaria. 2020. "Trends in FDA Drug Approvals over Last 2 Decades: An Observational Study.” Journal of Family Medicine and Primary Care 9 (1): 105. https://d oi.org/10.4103/ifmpc.jfmpc_578_19.
Rajkumar, S. Vincent. 2018. "Value and Cost of Myeloma Therapy." American Society of Clinical Oncology Educational Book 38 (May): 662-66. https://doi.org/1 0.1200/edbk_200867. 